\title{
경상남도 과수농민의 수근관 증후군과 동반된 척골신경병증
}

\author{
조홍식 ${ }^{1}$, 천세웅 ${ }^{2}$, 이은신 ${ }^{1}$, 윤철호 ${ }^{1}$, 신희석 $^{1}$, 이창한 $^{1}$
}

${ }^{1}$ 경상대학교 의학전문대학원 재활의학교실, ${ }^{2}$ 창원경상대학교병원 재활의학과

\section{Involvement of Motor and Sensory Fibers of the Ulnar Nerve according to the Severity of Work-Related Carpal Tunnel Syndrome among Orchardists}

\author{
Hongsik Jo ${ }^{1}$, Se-Woong Chun ${ }^{2}$, Eun Shin Lee ${ }^{1}$, Chulho Yoon ${ }^{1}$, Heesuk Shin ${ }^{1}$, Chang Han Lee ${ }^{1}$ \\ 'Department of Rehabilitation Medicine, Gyeongsang National University School of Medicine and \\ Gyeongsang National University Hospital, Jinju, ${ }^{2}$ Department of Rehabilitation Medicine, \\ Gyeongsang National University Changwon Hospital, Changwon, Korea
}

\begin{abstract}
Objective: To elucidate the involvement of motor and sensory fibers of the ulnar nerve in cases of work-related carpal tunnel syndrome (CTS) among orchardists and to determine the association between the severity of work-related CTS and ulnar neuropathy (UN).

Method: 1,594 hands of 797 subjects were underwent electrodiagnostic (EDX) tests for median and ulnar nerves. Subjects were classified into three groups: non-CTS, non-UN+CTS, and UN+CTS group. The CTS group was classified into subgroups of CTS severity.

Results: Significant differences were found in the conduction parameters of median and ulnar nerves $(p<0.001)$ among the three groups. Comparison of the mean values of non-CTS group and subgroups of CTS severity also showed significant differences in the conduction parameters of ulnar nerve $(p<0.05)$. In addition, the severity of CTS showed significant correlations with conduction parameters of the ulnar nerve $(p<0.05)$.

Conclusion: Based on the severity of work-related CTS, we suggest that the pathological processes leading to CTS may affect the motor and sensory fibers of the ulnar nerve.
\end{abstract}

Key Words: carpal tunnel syndrome, electrodiagnostic test, orchardists, ulnar neuropathy, work-related carpal tunnel syndrome

\section{Introduction}

Received October 12, 2017

Revised (1st) November 27, 2017, (2nd) December 19, 2017

Accepted December 28, 2017

Corresponding Author: Chang Han Lee

Department of Rehabilitation Medicine, Gyeongsang National University

Hospital, 79 Gangnam-ro, Jinju 52727, Korea

Tel: 82-55-750-8256, Fax: 82-55-750-8255, E-mail: ychkhk1407@gmail.com
The most common entrapment neuropathy, carpal tunnel syndrome (CTS), is characterized by compression of the distal median nerve within the anatomic area referred to as the carpal tunnel. It is highly related to occupations involving repeated movements and upper-
Copyright $\odot$ by Korean Association of EMG

Electrodiagnostic Medicine
This is an Open Access article distributed under the terms of the Creative Commons Attribution Non-Commercial License (http://creativecommons.org/licenses/by-nc/4.0) which permits unrestricted non-commercial use, distribution, and reproduction in any medium, provided the original work is properly cited. 
limb strength. ${ }^{1,2}$ Most patients complain of symptoms in the fingers and hand that extend beyond the typical median nerve distribution. Involvement of the ulnar nerve territory has often been observed in CTS.,3 Because of the close anatomical contiguity between the carpal tunnel and the Guyon's canal, pathologic processes that cause CTS might induce indirect compression of ulnar nerve. ${ }^{4,5}$ A few studies have reported about the coincidence of clinically involved little finger in CTS. ${ }^{1,6-8}$ These studies have been taken in the general population.

To the best of our knowledge and based on a comprehensive literature review, no published study has yet assessed the involvement of motor and sensory fibers of the ulnar nerve in work-related CTS. The purpose of our study is 1) to elucidate the involvement of motor and sensory fibers of the ulnar nerve in cases of CTS among orchardists who repeatedly use their wrists and hands and 2) to investigate any association between the severity of CTS and ulnar neuropathy (UN).

\section{Materials and Methods}

\section{1) Subjects}

As part of the Farmers' Health Promotion Project, a retrospective case-control study was performed by analyzing electrodiagnostic (EDX) test in orchardists who visited Gyeongsang National University Hospital Center for Farmer's Safety and Health between July 2013 and September 2014. The participants had repeatedly used their wrists and hands for a long time. They had no history or clinical signs suggesting systemic disease, clinical or electrophysiological signs suggesting pathological conditions such as polyneuropathy, radiculopathy, muscle atrophy following median and ulnar nerve surgery, and other neurological disease, or associated with CTS. Demographic and EDX test data for 797 subjects (378 males, 419 females) who satisfied the inclusion criteria were analyzed in the basic investigation. Demographic data included sex, age and total work time period. Based on the EDX results, we divided the hands of all subjects into non-CTS and CTS groups, The CTS group was divided into non-UN + CTS and UN + CTS groups, again. Patient consent was obtained from all the participants prior to the study, and the study was approved by the Institutional Review Board of our Hospital.

\section{2) Electrodiagnostic test}

All the subjects underwent EDX tests. A Medelec Synergy system (Oxford Instruments, Oxford, UK) was used for EDX studies with the subjects lying on a bed in a quiet and warm room, and the limb temperature maintained at $33^{\circ} \mathrm{C}$. Nerve conduction studies of median and ulnar nerves were performed as follows. Surface recording electrodes $(\mathrm{Ag} / \mathrm{AgCl})$ were placed over the motor point of the abductor digiti minimi muscle for the ulnar nerve, and over the abductor pollicis brevis muscle for the median nerve. The median nerve was stimulated at a distance of $8 \mathrm{~cm}$ from the active electrode, between the tendons of the flexor carpi radialis and palmaris longus muscles at the wrist and the elbow. The ulnar nerve was stimulated at the wrist at a distance of $8 \mathrm{~cm}$ for the abductor digiti minimi and at the elbow. The motor nerve conduction velocities (MCVs), distal motor latencies (DMLs), and compound muscle action potential (CMAP) amplitudes for median and ulnar nerves were calculated. The sensory never conduction studies were conducted by determining the sensory nerve action potential (SNAP) amplitudes and distal sensory latencies (DSLs) antidromically, using a ring electrode after wrist stimulation and registered at the third digit for the median nerve at a distance of 14 $\mathrm{cm}$ between the stimulator and the active electrode. SNAP amplitudes and DSLs for the ulnar nerve were obtained at the fifth digit similarly at a distance of 14 $\mathrm{cm}$ between the stimulator and active electrode.

A diagnosis of CTS in the EDX tests was defined as a median motor nerve distal latency exceeding $4.0 \mathrm{~ms}$ or a median sensory nerve distal latency exceeding $3.6 \mathrm{~ms}$, or by comparing the median sensory latency to digit IV with the ulnar sensory latency to the same 
digit, with the difference in distal latency exceeding 0.5 ms. ${ }^{9}$ Normal MCVs of the median nerve along the forearm were mandatory $(50 \mathrm{~m} / \mathrm{s})$. The EDX criteria of ulnar neuropathy (UN) included ulnar nerve DSLs > $3.5 \mathrm{~ms}$ and/or DMLs $>3.6 \mathrm{~ms}$ and/or SNAP amplitude $<15 \mu \mathrm{V}$ and/or CMAP amplitude $<7.9 \mathrm{mV} \cdot{ }^{10,11}$ The severity of CTS was classified as previously described ${ }^{12}$ as follows: normal (grade 0); very mild (grade 1), CTS demonstrable only with most sensitive test; mild (grade 2), sensory nerve conduction velocity slow on finger/ wrist measurement, normal terminal latency; moderate (grade 3 ), sensory potential preserved with motor slowing, distal motor latency to APB $<6.5 \mathrm{~ms}$; severe (grade 4), absent sensory potential but preserved motor response, distal motor latency to $\mathrm{APB}<6.5 \mathrm{~ms}$; very severe (grade 5), terminal latency to $\mathrm{APB}>6.5 \mathrm{~ms}$; extremely severe (grade 6), sensory and motor potential effectively unrecordable (surface motor potential ranging from $\mathrm{APB}<0.2 \mathrm{mV}$ amplitude).

\section{3) Data analysis}

Statistical analyses were conducted using SPSS version 21.0 (IBM, Armonk, NY, USA). Arithmetic mean values and standard deviation for different variables were measured. One way analysis of variance (ANOVA) and the Pearson chi-squared test comparing sex among three groups were done to compare demographic characteristics. The total work period was assessed with the analysis of covariance (ANCOVA) procedure. The covariate was age. Comparison of the EDX parameters among three groups was investigated using oneway ANOVA. The Bonferroni post hoc test was per- formed to identify the differences between the groups. A repeated measure of ANOVA was applied to compare differences of EDX parameters according to the Bland classification. ${ }^{12}$ Spearman correlation coefficients and the corresponding $\mathrm{p}$-values were used to evaluate the relationships between the severity of CTS based on Bland classification and conduction parameters of the ulnar nerve in the CTS group. A p-value of 0.05 was considered statistically significant.

\section{Results}

\section{1) General characteristics of the subjects}

We studied 1,594 hands of a total of 797 subjects aged between 29 and 80 years (mean 59.6 years). 271 subjects had bilateral CTS, 55 had right-sided CTS, and 47 had left-sided CTS. Among 1,594 hands, 950 hands were diagnosed normal in EDX test. A total of 644 symptomatic hands in 373 subjects were diagnosed with CTS. In the CTS group, non-UN and UN groups were 398 and 246 hands, respectively. The general characteristics of each group are presented in Table 1. There were significant differences among the three groups in sex, age and total work period. Post-hoc testing revealed that in the UN + CTS group $(\mathrm{p}<0.001)$, age and total work period were significantly higher than those in the non-CTS and non-UN + CTS groups. In addition, after adjusting for age, ANCOVA revealed significant differences among the three groups in the total work period $(\mathrm{p}<0.05)$.

Table 1. Demographic and Baseline Characteristics among Three Groups

\begin{tabular}{lcccc}
\hline \hline \multicolumn{1}{c}{ Characteristics } & $\begin{array}{c}\text { Non-CTS group } \\
(\mathrm{n}=950)\end{array}$ & \multicolumn{2}{c}{ CTS group } & $\mathrm{p}$-value \\
\cline { 3 - 4 } & & $\mathrm{non}$-UN $(\mathrm{n}=398)$ & & \\
\hline Number of hands $(\mathrm{n})$ & $462 / 485$ & $128 / 270$ & $200 / 46)$ & $<0.001^{*}$ \\
Male/Female & $58.3 \pm 9.11$ & $60.1 \pm 7.88$ & $64.9 \pm 6.36^{+, \neq}$ & $<0.001^{*}$ \\
Age (y) & $28.3 \pm 13.95$ & $32.2 \pm 13.56$ & $35.5 \pm 14.98^{+, \neq}$ & $0.037^{*, 8}$ \\
Total work period (y) &
\end{tabular}

Values are shown as mean \pm SD, or as otherwise indicated. CTS: carpal tunnel syndrome, UN: ulnar neuropathy ${ }^{*} p<0.05$ is significant, ${ }^{\dagger}$ Significantly different compared with the non-CTS group, ${ }^{\ddagger}$ Significantly different compared with CTS+non-UN group, ${ }^{8} \mathrm{p}^{\text {ANCOVA }}$ : $\mathrm{p}$-value of ANCOVA (covariate $=$ age) 


\section{2) Conduction parameters for both median and ulnar nerves among three groups}

There were significant differences of all EDX parameters except of CMAP amplitude of ulnar nerve among three groups $(\mathrm{p}<0.05$, Table 2$)$. The post-hoc testing revealed that in the UN + CTS group, all EDX parameters except of CMAP amplitude of ulnar nerve were significantly different from those in the non-CTS groups ( $<$ 0.001). There were significant differences of DMLs, MCVs, and SNAP amplitude of median nerve between non-UN + CTS and UN + CTS groups $(\mathrm{p}<$ 0.001).

\section{3) Conduction parameters for ulnar nerve between non-CTS group and subgroups of CTS}

According to the Bland classification criteria, 139 hands were classified as grade 1,218 as grade 2, 268 as grade 3, 9 as grade 4, and 10 as grade 5. Repeated ANOVA revealed significant differences in the mean values of EDX parameters for the ulnar nerve between the non-CTS group (grade 0) and subgroups of CTS ( $p$ $<0.05$, Table 3).

\section{4) Correlations between severity of CTS and conduction parameters of ulnar nerve in CTS Group}

The severity of CTS by Bland classification and all

Table 2. Conduction Parameters for Both Median and Ulnar Nerves among Three Groups

\begin{tabular}{|c|c|c|c|c|}
\hline \multirow{2}{*}{ Variable } & \multirow{2}{*}{$\begin{array}{l}\text { Non-CTS group } \\
\quad(n=950)\end{array}$} & \multicolumn{2}{|c|}{ CTS group } & \multirow{2}{*}{$p$-value } \\
\hline & & non-UN (n = 398) & UN $(n=246)$ & \\
\hline \multicolumn{5}{|l|}{ Median nerve } \\
\hline DMLs (ms) & $3.26 \pm 0.38$ & $4.06 \pm 0.75$ & $4.33 \pm 1.16^{\dagger, \neq}$ & $<0.001^{*}$ \\
\hline CMAP amplitude (mV) & $14.13 \pm 3.85$ & $12.59 \pm 3.76$ & $12.34 \pm 4.09^{\dagger}$ & $<0.001^{*}$ \\
\hline MCVs $(\mathrm{m} / \mathrm{s})$ & $57.11 \pm 5.47$ & $54.93 \pm 5.19$ & $51.74 \pm 5.16^{\dagger, \neq}$ & $<0.001^{*}$ \\
\hline DSLs (ms) & $3.38 \pm 1.47$ & $4.07 \pm 2.05$ & $4.34 \pm 1.27^{\dagger}$ & $<0.001^{*}$ \\
\hline SNAP amplitude $(\mu \mathrm{V})$ & $33.48 \pm 14.24$ & $26.17 \pm 12.42$ & $20.24 \pm 10.85^{+, \neq}$ & $<0.001^{*}$ \\
\hline \multicolumn{5}{|l|}{ Ulnar nerve } \\
\hline DMLs (ms) & $2.53 \pm 0.38$ & $2.58 \pm 0.32$ & $2.98 \pm 0.53^{\dagger, \ddagger}$ & $<0.001^{*}$ \\
\hline CMAP amplitude (mV) & $13.79 \pm 3.03$ & $13.60 \pm 2.77$ & $13.36 \pm 4.64$ & 0.292 \\
\hline $\mathrm{MCVs}(\mathrm{m} / \mathrm{s})$ & $62.73 \pm 8.04$ & $61.11 \pm 6.57$ & $56.23 \pm 6.29^{+, \neq}$ & $<0.001^{*}$ \\
\hline DSLs (ms) & $3.06 \pm 0.37$ & $3.08 \pm 0.34$ & $3.71 \pm 0.67^{+, \neq}$ & $<0.001^{*}$ \\
\hline SNAP amplitude $(\mu \mathrm{V})$ & $30.15 \pm 17.94$ & $29.10 \pm 10.36$ & $17.30 \pm 9.63^{+, \neq}$ & $<0.001^{*}$ \\
\hline
\end{tabular}

Values are shown as mean $\pm \mathrm{SD}$, or as otherwise indicated

CTS: carpal tunnel syndrome, UN: ulnar neuropathy, DMLs: distal motor latencies, CMAP: compound muscle action potential, MCVs: motor nerve conduction velocities, DSLs: distal sensory latencies, SNAP: sensory nerve action potential

${ }^{*} \mathrm{p}<0.05$ is significant, ${ }^{\dagger}$ Significantly different compared with the non-CTS group, ${ }^{\ddagger}$ Significantly different compared with CTS + non-UN group

Table 3. Conduction Parameters for Ulnar Nerve between Non-CTS Group and Subgroups of CTS

\begin{tabular}{|c|c|c|c|c|c|c|c|}
\hline \multirow{2}{*}{ Bland scale } & \multirow{2}{*}{$\begin{array}{c}\text { Non-CTS group } \\
\text { Gr } 0(n=950)\end{array}$} & \multicolumn{5}{|c|}{ CTS group } & \multirow{2}{*}{$p$-value } \\
\hline & & Gr $1(n=139)$ & Gr $2(n=218)$ & $\operatorname{Gr} 3(n=268)$ & Gr $4(n=9)$ & $\operatorname{Gr} 5(n=10)$ & \\
\hline \multicolumn{8}{|l|}{ Ulnar nerve } \\
\hline DMLs (ms) & $2.52 \pm 0.38$ & $2.45 \pm 0.35$ & $2.70 \pm 0.39$ & $2.77 \pm 0.44$ & $2.69 \pm 0.37$ & $3.19 \pm 0.47$ & $<0.001 *$ \\
\hline CMAP amplitude (mV) & $13.79 \pm 3.03$ & $13.59 \pm 2.78$ & $13.68 \pm 4.03$ & $13.51 \pm 2.97$ & $11.26 \pm 3.67$ & $11.12 \pm 4.46$ & $0.020 *$ \\
\hline $\operatorname{MCVs}(\mathrm{m} / \mathrm{s})$ & $62.73 \pm 8.04$ & $61.90 \pm 6.64$ & $59.17 \pm 5.91$ & $59.20 \pm 6.94$ & $58.37 \pm 3.63$ & $57.32 \pm 2.41$ & $<0.001 *$ \\
\hline DSLs (ms) & $3.06 \pm 0.37$ & $2.94 \pm 0.36$ & $3.30 \pm 0.37$ & $3.36 \pm 0.60$ & $3.41 \pm 1.19$ & $3.41 \pm 0.42$ & $<0.001^{*}$ \\
\hline SNAP amplitude $(\mu \mathrm{V})$ & $30.15 \pm 17.95$ & $27.19 \pm 12.23$ & $25.69 \pm 10.82$ & $25.74 \pm 11.45$ & $19.43 \pm 9.33$ & $25.15 \pm 9.75$ & $<0.001^{*}$ \\
\hline
\end{tabular}

Values are shown as mean $\pm \mathrm{SD}$, or as otherwise indicated

CTS: carpal tunnel syndrome, Gr: grade, DMLs: distal motor latencies, CMAP: compound muscle action potential, MCVs: motor nerve conduction velocities, DSLs: distal sensory latencies, SNAP: sensory nerve action potential

${ }^{*} \mathrm{p}<0.05$ is significant 
Table 4. Spearman's Correlation Coefficient of the Severity of CTS and Conduction Parameters of the Ulnar Nerve in the CTS Group

\begin{tabular}{lcc}
\hline \hline & \multicolumn{2}{c}{ Severity of CTS (Bland Scale) } \\
\cline { 2 - 3 } & Correlation coefficient & $\mathrm{p}$-value \\
\hline Ulnar nerve & & \\
DMLs & 0.240 & $<0.001^{*}$ \\
CMAP amplitude & -0.052 & $0.038^{*}$ \\
MCVs & -0.193 & $<0.001^{*}$ \\
DSLs & 0.211 & $<0.001^{*}$ \\
SNAP amplitude & -0.142 & $<0.001^{*}$ \\
\hline
\end{tabular}

CTS: carpal tunnel syndrome, DMLs: distal motor latencies, CMAP: compound muscle action potential, MCVs: motor nerve conduction velocities, DSLs: distal sensory latencies, SNAP: sensory nerve action potential

$* p<0.05$ is significant

EDX parameters of the ulnar nerve were significantly correlated $(p<0.05$, Table 4).

\section{Discussion}

The distribution of sensory symptoms associated with CTS varies. Symptoms are considered to be located primarily in the median distribution. But sometimes pain extends to the ulnar nerve territory. ${ }^{13,14}$ The first description of ulnar nerve entrapments associated with CTS came from Sedal et al. ${ }^{4}$ Ulnar nerve involvement was reported in $44 \%$ of the patients. Other studies also showed an association between CTS and impairment of ulnar sensory nerve fibers. ${ }^{15}$ Cassvan et al. ${ }^{7}$ performed a retrospective study. The study included 248 patients, of whom 114 patients (46\%) had delayed ulnar SNAP peak latency at the wrist. The exact mechanism for the ulnar nerve involvement in CTS patients is unclear. Tecchio et al. ${ }^{16}$ reported evidence of enlargement of the hand representation in the sensory cortex in CTS patients, which supports the hypothesis of central plasticity mechanisms producing an extra-median spread of symptoms. Another possible mechanism is damage to ulnar nerve axons in CTS patients. This may be caused indirectly by compressive forces transmitted to the ulnar nerve by high pressure in the carpal tunnel. Increased carpal tunnel pressure in CTS patients may exert mechanical traction in the transverse carpal ligament.
Because the fibers of the transverse carpal ligament form the medial wall and floor of the Guyon's canal, volumetric and pressure increases in Guyon's canal have been documented in CTS patients. ${ }^{17-19}$ Ulnar nerve abnormalities may be attributable to morphological (focal nerve demyelination) or functional (membrane potential and ion channel changes) factors. However, spontaneous relief of ulnar symptoms in CTS patients following surgical decompression of the carpal tunnel alone suggests that functional rather than morphological factors are mainly responsible for the ulnar nerve abnormalities. ${ }^{15,17}$ However, a few reports exclude the association between CTS and ulnar nerve entrapment at wrist. Vahdatpour et al. ${ }^{20}$ reported that concomitant ulnar nerve compromise was much lower than the incidence reported in prior studies. Moghtaderi and Ghafarpoor ${ }^{21}$ suggested that there might not be any association between CTS and ulnar nerve compression at the wrist. Similarly, electrophysiological studies provided different results. Further, different techniques, such as dissimilar cutoff values, selection of dorsal ulnar cutaneous sensory test, orthodromic inching test and increasing age, have been reported as probable causes of the different ulnar nerve conduction values. ${ }^{22,23}$

We performed this study in among orchardists whose work requires repetitive bending of the wrist or forceful clenching of the hand while using scissors for pruning or during fruit collection. The prevalence of CTS diagnosed by EDX test was $40.4 \%$ in this study. This proportion is higher than the prevalence in highrisk occupational groups (6.5\%, 23.5 26\%, 29.4\%, and $16.9 \%$ for telephone exchange operators, meatprocessing workers, workers in the wood-processing industry, and residents working in agricultural area, respectively). ${ }^{24-27}$ Considering characteristics related to CTS, sex, age and total work period significantly contributed to the development of CTS $(p<0.05)$. The three groups of subjects (non-CTS, non-UN + CTS, and $\mathrm{UN}+\mathrm{CTS})$ varied significantly in age $(\mathrm{p}<0.001)$. It's also known the conduction velocity and amplitude of the peripheral nerves decreases with increasing age. ${ }^{28}$ 
This can be another bias. However, we conducted this study in among orchardists who had to work at least several hours a day for the purpose of maintain their life. Especially, in the UN + CTS group, age and total work period were significantly higher than that of other groups ( $\mathrm{p}<0.001)$. Age and total work period seemed to affect UN as well as CTS $(p<0.05)$. These results assumed that the older age, the more total work period was increased and as result, these repeated use of wrist and hand expose them to a high risk of UN as well as CTS. Also within CTS group, there were differences of male/female ratio between non-UN and UN groups, respectively. At non-UN + CTS group, that involved only CTS, females were dominant ( $\mathrm{M}: \mathrm{F}=128: 270)$. These results support previous observations suggesting that the risk of developing CTS generally increases in middle-aged women. ${ }^{29}$ But at UN + CTS group, males were dominant ( $\mathrm{M}: \mathrm{F}=200: 46)$. These results support previous observations that age-dependent changes in ulnar MCVs were more prominent in males than in females. ${ }^{30}$

And we identified the significant involvement of motor and sensory fibers of ulnar nerve in cases of CTS among orchardists. 246 of 644 hands with CTS (38.2\%) was detected the involvement of ulnar nerve. In the UN + CTS group, all EDX parameters except of CMAP amplitude of ulnar nerve were significantly different from those in the non-CTS groups $(\mathrm{p}<0.001)$. And, CMAP amplitudes of ulnar nerve in the UN + CTS group were lower than that of non-CTS group, although there were no significant differences between the two groups $(13.79 \pm 3.03$ vs $13.36 \pm 4.64, p>0.05)$. In addition, there were significant differences in DMLs, MCVs and SNAP amplitude of the median nerve between the non-UN + CTS and UN + CTS group in the CTS group $(p<0.001)$. These results show that group with UN in CTS had more severely median nerve impairment compared to non-UN in CTS. The differences in ulnar conduction parameters between the CTS and nonCTS groups were evident according to the severity of CTS ( $<0.05)$. Ulnar CMAP amplitudes of grade 4 and
5 were particularly lower than that of grade 1,2, and 3. Actually, more than half of CTS groups were consist of grade 1, 2, and 3. In light of these, percentage of involvement of ulnar nerve would have increased, if more numbers of grade 4 and 5 had detected. Maybe there would be significant difference in the CMAP amplitude of ulnar nerve. In addition, the present study showed that the severity of CTS was correlated with ulnar EDX parameters. These findings also supported that the severity of CTS would affect ulnar sensory and motor impairment. The exact mechanism for the ulnar nerve involvement in CTS patients is unclear. But the prevalence of CTS diagnosed by EDX test was higher than that in high-risk occupational groups in this study. The strong association between the severity of CTS and UN may be related to the increased carpal tunnel pressure in CTS patients exerting mechanical traction in the transverse carpal ligament. Consequentially, we may think that volumetric and pressure increases in Guyon's canal may come to pass in CTS among orchardists.

Yemisci et al. ${ }^{3}$ first reported changes in the motor as well as sensory fibers of ulnar nerve in CTS among general population. Since then, motor impairment of ulnar nerve in the CTS has not been studied. Most studies mentioned so far showed ulnar nerve involvement in cases of CTS among general population. In these, only sensory impairment of the ulnar nerve increased in the CTS patients. ${ }^{4,7,8,15,20}$ The present study documents motor fibers as well as sensory fibers impairment of ulnar nerve. This is the first study to show the changes in not only the sensory fibers but also the motor fibers in work-related CTS among orchardists. But ulnar CMAP amplitude not significantly correlated with median DMLs/DSLs. This may be explained that sensory fibers are more susceptible to mechanical stress than motor fibers. ${ }^{31}$

Several limitations of this study should be considered. First, there was no segmental conduction study around the elbow or a conduction study in the dorsal ulnar cutaneous nerve. Therefore, we cannot completely rule 
out the involvement of the ulnar nerve at the elbow, forearm, and wrist. Second, the data were derived from a single EDX center. Electrophysiological studies may yield different results based on other variables. Third, participants who were not diagnosed with other neurological diseases were excluded from our study of CTS and UN-related symptoms. A few items in the population analysis including the presence of clinical symptoms were difficult to confirm in the screening due to the large-scale investigation. Moreover, in our study, several demographics data were significantly different among three groups. As each group was divided into groups of hand according to EDX parameters, so even in the same patient, the group may differ according to the result of the EDX test of the right hand and the left hand. These confused on interpretation of demographic data. Therefore, to avoid contradictory results, we need to consider patient selection, study design, differences in race and job, undiagnosed peripheral polyneuropathy, and so on. Further research is needed to generalize our results after adjusting for other variables.

\section{Conclusion}

The present study reports an association between work-related CTS and involvement of motor and sensory fibers of the ulnar nerve in orchardists. Ulnar nerve involvement is associated with moderate and severe CTS among orchardists. Considering that orchardists use their hands and wrists repetitively, it is plausible that the actions result in damage to ulnar nerve axons in CTS patients among the various possible mechanisms. In other words, ulnar nerve damage may be caused indirectly by compressive forces transmitted to the ulnar nerve by high pressure in the carpal tunnel. Regarding work-related CTS, pathological events leading to work-related CTS may affect the motor and sensory fibers of the ulnar nerve. Additional research is needed to demonstrate this mechanism.

\section{References}

1. Stevens JC, Smith BE, Weaver AL, Bosch EP, Deen HG, Wilkens JA: Symptoms of 100 patients with electromyographically verified carpal tunnel syndrome. Muscle nerve 1999: 22: 1448-1456

2. Herbert R, Gerr F, Dropkin J: Clinical evaluation and management of work-related carpal tunnel syndrome. American Journal of industrial medicine 2000: 37: 62-74

3. Yemisci OU, Yalbuzdag SA, Cosar S, Oztop P, Karatas M: Ulnar nerve conduction abnormalities in carpal tunnel syndrome. Muscle nerve 2011: 44: 352-357

4. Sedal L, McLeod J, Walsh J: Ulnar nerve lesions associated with the carpal tunnel syndrome. J Neurol Neurosurg Psychiatry 1973: 36: 118-123

5. Gelberman RH, Hergenroeder PT, Hargens AR, Lundborg GN, Akeson WH: The carpal tunnel syndrome. A study of carpal canal pressures. J Bone Joint Surg Am 1981: 63: 380383

6. Gupta SK, Benstead TJ: Symptoms experienced by patients with carpal tunnel syndrome. Can J Neurol Sci 1997: 24: 338-342

7. Cassvan A, Rosenberg A, Rivera LF: Ulnar nerve involvement in carpal tunnel syndrome. Arch Phys Med Rehabil 1986: 67: 290-292

8. Gozke E, Dortcan N, Kocer A, Cetinkaya M, Akyuz G, Us O: Ulnar nerve entrapment at wrist associated with carpal tunnel syndrome. Clin Neurophysiol 2003: 33: 219-222

9. Johnson E, Kukla R, Wongsam P, Piedmont A: Sensory latencies to the ring finger: normal values and relation to carpal tunnel syndrome. Arch Phys Med Rehabil 1981: 62: 206-208

10. Johnson E, Melvin JL: Sensory conduction studies of median and ulnar nerves. Arch Phys Med Rehabil 1967: 48: 25-30

11. Buschbacher RM, Ralph M: Ulnar motor nerve conduction to the abductor digiti minimi. Am J Phys Med Rehabil 1999: 78: S9-S14

12. Bland JD: A neurophysiological grading scale for carpal tunnel syndrome. Muscle Nerve 2000: 23: 1280-1283

13. Werner RA, Andary M: Carpal tunnel syndrome: pathophysiology and clinical neurophysiology. Clin Neurophysiol 2002: 113: $1373-1381$

14. Caliandro P, La Torre G, Aprile I, Pazzaglia C, Commodari I, Tonali $\mathrm{P}$, et al: Distribution of paresthesias in carpal tunnel syndrome reflects the degree of nerve damage at wrist. Clin neurophysiol 2006: 117: 228-231

15. Silver MA, Gelberman RH, Gellman H, Rhoades CE: Carpal tunnel syndrome: associated abnormalities in ulnar nerve 
function and the effect of carpal tunnel release on these abnormalities. J Hand Surg 1985: 10: 710-713

16. Tecchio F, Padua L, Aprile I, Rossini PM: Carpal tunnel syndrome modifies sensory hand cortical somatotopy: a MEG study. Hum Brain Mapp 2002: 17: 28-36

17. Ablove R, Moy O, Peimer C, Wheeler D, Diao E: Pressure changes in Guyon's canal after carpal tunnel release. J Hand Surg Eur Vol 1996: 21: 664-665

18. Ablove RH, Peimer CA, Diao E, Oliverio R, Kuhn JP: Morphologic changes following endoscopic and two-portal subcutaneous carpal tunnel release. J Hand Surg 1994: 19: 821826

19. Richman JA, Gelberman RH, Rydevik BL, Hajek PC, Braun RM, Gylys-Morin VM, et al: Carpal tunnel syndrome: morphologic changes after release of the transverse carpal ligament. J Hand Surg 1989: 14: 852-857

20. Vahdatpour B, Raissi G, Hollisaz M: Study of the ulnar nerve compromise at the wrist of patients with carpal tunnel syndrome. Electromyogr Clin Neurophysiol 2006: 47: 183-186

21. Moghtaderi A, Ghafarpoor M: The dilemma of ulnar nerve entrapment at wrist in carpal tunnel syndrome. Clin Neurol Neurosurg 2009: 111: 151-155

22. Landau ME, Barner KC, Campbell WW: Effect of body mass index on ulnar nerve conduction velocity, ulnar neuropathy at the elbow, and carpal tunnel syndrome. Muscle Nerve 2005: 32: 360-363

23. Kim DH, Kang YK, Hwang M, Kwon HK, Lee HJ, Kim BG: Reference values of fractionated neurography of the ulnar nerve at the wrist in healthy subjects. Clin Neurophysiol
2005: 116: 2853-2857

24. Lee JM, Kim SK, Kim JM: Carpal tunnel syndrome in meatprocessing workers. Korean J Occup Environ Med 1999: 11: 407-414

25. Sohn MK, Kim BO, Yune SH: Prevalence and Diagnostic Value of Nerve Conduction Study as a Screening of Carpal Tunnel Syndrome in Industry. J Korean Acad Rehabil Med 1997: 21: $112-120$

26. Lee J, Kwon YW, Choi JC, Choi JH, Lim HS, Kim SK: Prevalence of and Risk factors for carpal tunnel syndrome in a rural population. J Korean Acad Rehabil Med 2001: 25: 818826

27. Son JE, Jang TW, Kim YK, Hong YS, Jung KY, Kim DI, et al: Survey on the prevalence of carpal tunnel syndrome in simple repetitive workers who use upper extremities. Korean J Occup Environ Med 2001: 13: 209-219

28. Jagga M, Lehri A, Verma SK: Effect of aging and anthropometric measurements on nerve conduction properties-A review. J Excercise Sci Physiother 2011: 7: 1

29. Aroori S, Spence RA: Carpal tunnel syndrome. Ulster Med J 2008: 77: 6-17

30. Kommalage M, Gunawardena S: Influence of age, gender, and sidedness on ulnar nerve conduction. J Clin Neurophysiol 2013:30: 98-101

31. Lin CSY, Kuwabara S, Cappelen-Smith C, Burke D: Responses of human sensory and motor axons to the release of ischaemia and to hyperpolarizing currents. J Physiol 2002: 541: 1025-1039 